\title{
Online Education: Prospects of Development in Russia
}

\author{
Natalia A. Zakharova*, Anastasiya F. Yudintseva \\ Kazan Federal University, Russia
}

Received July 12, 2019; Revised September 20, 2019; Accepted September 27, 2019

Copyright $(2019$ by authors, all rights reserved. Authors agree that this article remains permanently open access under the terms of the Creative Commons Attribution License 4.0 International License

\begin{abstract}
Nowadays two mainstreams of "Globalization of online education" and "Its individualization" can be observed in the area of distance and online education. This article aimed at outlining some possibilities of foreign-language online courses that meet the trends mentioned above, as well as identifying tendencies in the development of distance education in Russia. Our paper is devoted to the analysis of MOOC market, both on a national as well as a worldwide basis. MOOCs integrate virtual educational space at the global level and their main characteristics include massive involvement, openness, online interaction between students and teachers in chats, video conferences, forums, automatic assessment of student performance while performing tests, and the system of mutual evaluation of each other's works by students. To further investigate the subject, the following methods were used: system analysis, synthesis, and generalization, as well as the method of comparison when identifying main trends in the development and dissemination of MOOC.
\end{abstract}

Keywords MOOC, Online Course, Research, Education, Distant Learning

\section{Introduction}

The movement for open education appeared in the second half of the XX century with the goal of providing a wide access to educational materials and creating opportunities of receiving education for almost everyone. It has received a new image in the XX1 century in the form of massive open online courses (MOOC).

The English term MOOC was first used by D. Komier in 2008 when discussing with his colleagues S. Downes and D. Siemens about his online course "Connectivism and Connective Knowledge", which was actually the first MOOC. Ideas for open online courses and the possibility of registering people who are not students of a specific university were expressed even before this course started.
But the way it was technically implemented allowed thousands of students to be trained simultaneously [5] which was a distinctive feature of such a project. The course devoted to the incomprehensible theory of connectivism was registered by 2300 students that exceeded the researchers' expectations almost ten times which made it possible to call it the first mass open online course.

Nowadays, a great number of commercial and non-profit organizations are involved in the development and provision of MOOCs. The process of creating them takes place within international cooperation of prominent universities and other educational institutions throughout the world. For example, at the beginning of 2018, 24 million users and more than 2,000 courses from over 150 educational institutions were registered with Coursera. Class Central (the largest aggregator of MOOC which analyzes major changes and trends in mass open online courses annually) in its seventh year of existence announced that massive open online courses covered 900 universities and collected 101 million users from all over the world [16]. At the same time, the number of those who first registered on online learning platforms has been decreased significantly. Today, the audience for Coursera, edX and Udacity platforms, which started in the USA in 2011-2012, is estimated at millions of people, while in other countries there are similar projects that implement learning through MOOC.

\section{Methodological Framework}

The aim of this study is to identify challenging factors for MOOC from both foreign students and students or teachers from Russian universities. We considered their purposes of studying MOOC, and then analyzed the main advantages and disadvantages of such a training. Such methods as system analysis, synthesis and generalization as well as the method of comparison when identifying main trends in the development and dissemination of MOOC were used. 
The study used the following data sources: articles, reports, information from sites with online platforms, a database of quantitative data collected from two leading online platforms, a quantitative database from the Class Central aggregator, which provides information on the MOOCs hosting on several major online platforms.

Although MOOC is based on theoretical foundations of distance education and e-learning, it is still a less known phenomenon in pedagogy. This research highlights the use of a subject-language approach in creating MOOC, which can open new perspectives for the use of this type of training.

\section{Findings}

Regardless of the MOOC format, one can distinguish indisputable advantages of this type of training in addition to the relevant disadvantages.

The main advantages of MOOC are accessibility, widespread involvement of students, as well as implementation of lifelong learning principles. Currently, MOOCs are able to provide easy access, plus a free and flexible training schedule without major initial requirements for participation [1]. The main goal of MOOC is attracting students, improving student performance, and finally expanding their educational practice. MOOC encourages the "lifelong learning" system, forcing students to think about their learning goals and the significance of their own learning and education.

On the other hand, due to MOOC, no direct contact even through emails has been held between the students and teachers. As many researchers have noted, a high percentage of self-exclusion seems to be a major problem of initial dropping out. Despite the high dropout rates, the overall goal of MOOC can be achieved via a large number of course participants. For example, if ten thousand people enrolled in a course and only $20 \%$ could master it successfully, it's still 2,000 students, which exceeds the number of students in the regular courses of many classical universities [2]. Another consequence of mass character is the complexity of the knowledge control organization. In a majority of courses, the final test is carried out by multiple-choice tasks, which are not suitable for checking critical thinking skills and solving problems where there is no correct answer.

Creating a MOOC requires the involvement of a wide range of specialists and the subject-language integrated learning has been booming in recent years in Europe which is aimed at ensuring EU citizens' mobility in particular. The subject-language integrated $\mathrm{MOOC}$ is a multi-purpose concept not only in terms of learning but also in relation to the audience. There are three main target groups: Russian students, Russian teachers, and foreign audiences.

The evolution of MOOC in Russia follows the same path as other countries: from open educational resources and fee-based distance courses to the creation of Russian Internet sites offering MOOCs in addition to the placement of the Russian-speaking MOOC on the world's leading platforms. MOOC integration into the Russian educational domain needs to be considered from several perspectives: use of the existing MOOCs (both in Russian and foreign languages) and creation of new MOOCs, MOOC as a part of undergraduate/ specialist/ graduate programs, MOOC for advanced training, and self-improvement or lifelong learning. It is worth mentioning that the latter is a widespread phenomenon both in Russia and abroad.

Speaking about the use of MOOCs in higher professional education curriculums, we can distinguish two areas of obtaining credit units and the organization of independent work of students. If the first is the prerogative of the educational authorities, the second is the responsibility of a teacher. Modern federal state standards of higher vocational education imply large volumes of students' independent work, which requires a teacher to develop training materials and forms for organizing such type of tasks [11].

Using an existing MOOC requires additional training of the teacher which can be either passing the MOOC at the stage of selecting an appropriate course or working with the course materials simultaneously. The use of a MOOC for independent work is limited to a number of factors such as a small number of MOOCs in Russian, the uneven thematic distribution namely there are many more courses on technical, economic and natural sciences than on humanitarian ones, and a mismatch of the curriculum with the starting date of a MOOC.

One of the possibilities for creating a MOOC is to adapt existing courses made in virtual educational environment (for example in Moodle system) for a large number of users. Another way is to start partnership with Russian MOOC platforms, which provide technical support for creation of MOOCs.

The most popular platforms are Coursera, edX, and Udacity. In 2018 Coursera was the leader, functioning since the spring of 2012, and by the year 2018 it had announced 27 million students, participation of 150 partner universities, and 3100 active courses in hundreds of specializations [12]. According to Forbes, Coursera's estimated income in 2018 is $\$ 140$ million [15].

Since 2013 Coursera has been cooperating with Russian universities. On this platform, 290 online courses besides specializations from Russian universities and companies are available. This is almost $10 \%$ of the total number of courses hosted by Coursera partners from 28 countries. 215 Coursera Russian partners' courses are created in Russian. This is three-quarters of the total number. The remaining quarter (75 courses) are developed in English. Some courses are combined in a total of sixteen specializations. According to Coursera, exactly half of the students from Russia attend courses only in Russian (Figure 1). 


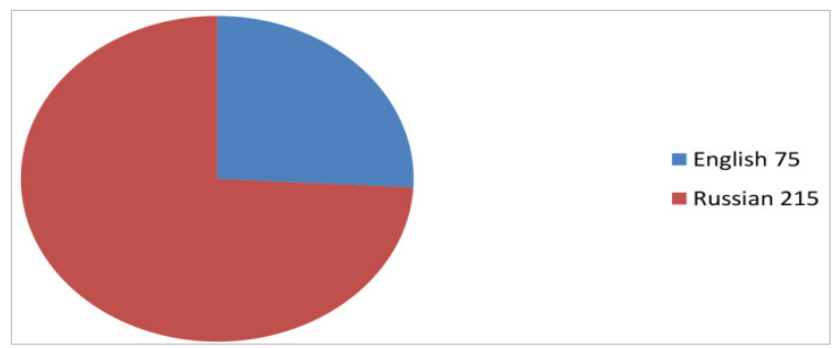

Figure 1. The number of Russian and English courses on the Coursera platform

Most Russian courses are devoted to the exact sciences such as computer science, science, engineering, and data analysis. Also, the most popular areas include business and social sciences. Most of the courses developed by Russians in English language are popular with foreigners. According to Coursera, $93 \%$ of students of English-speaking Russian courses are not from Russia. Last year, Russia became the largest non-English-speaking region in Coursera [16].

The Russian online education market has begun to develop actively since 2013, and according to J'son \& Partners Consulting, its volume in 2014 amounted to several million listeners, and the projects were presented by more than 50 companies [12]. The size of the online education market in Russia at the end of 2016 was estimated at 20.7 million rubles or $1.1 \%$ of all educational services. In higher education, the volume of the market for all distance learning programs was about 6.8 million rubles, and the share of online courses was $1.8 \%$.

The appearance on the MOOC market significantly changes the situation in modern education, for example its user-friendliness is increasing [3], and the structure of universities is being updated. At the same time, some authors are wondering if $\mathrm{MOOK}$ is a potential threat to modern universities [4]. Under these conditions, it is important to understand how the demand for MOOC in Russia is being formed, primarily from students and university professors.
Despite the fact that in the seventh year of its existence, massive open online courses covered 900 universities and gathered 101 million users from around the world, the number of those who first registered on the online learning platforms has fallen down $[13 ; 18]$

In 2018, at least one MOOC registered 20 million new users while in comparison, in the years 2017, and 2016, 23 million people came to online learning platforms. Despite this, the number of users willing to pay for online training has significantly increased. Apparently, the monetization model of the MEP platforms pays back. Providers such as Coursera receive record revenues.

This segment of the education market is headed by the largest MOOC platforms. Coursera remains the absolute leader in the number of registered users. In 2018, it reached 37 million students. Traditionally, this is two times more than second-place edX (Figure 2).

The most popular providers of MOOCs are such American platforms as Coursera, edX, and Udacity, as well as the British FutureLearn. In many countries, national online platforms have appeared: XuetangX in China, MiriadaX in Latin America, France Université Numérique in France, EduOpen in Italy, SWAYAM in India, and National Open Education Platform in Russia. In 2017, the Chinese online provider XuetangX ranked third in the number of listeners (9.3 million), ahead of FutureLearn (7.1 million) $[14 ; 19]$.

In addition, the placement of MOOCs on international platforms is becoming a way of popularizing the culture of different countries and a tool for raising the status of national higher education systems in the world. A number of countries, primarily Asian countries such as China, South Korea, or Malaysia are today putting forward the MOOC creation, as well as their deployment and promotion on foreign online platforms as one of the main strategic objectives at the state level. They hope to create a higher education system highly appreciated by the world community in the near future to be able to compete with the world's leading educational systems $[10 ; 17]$.

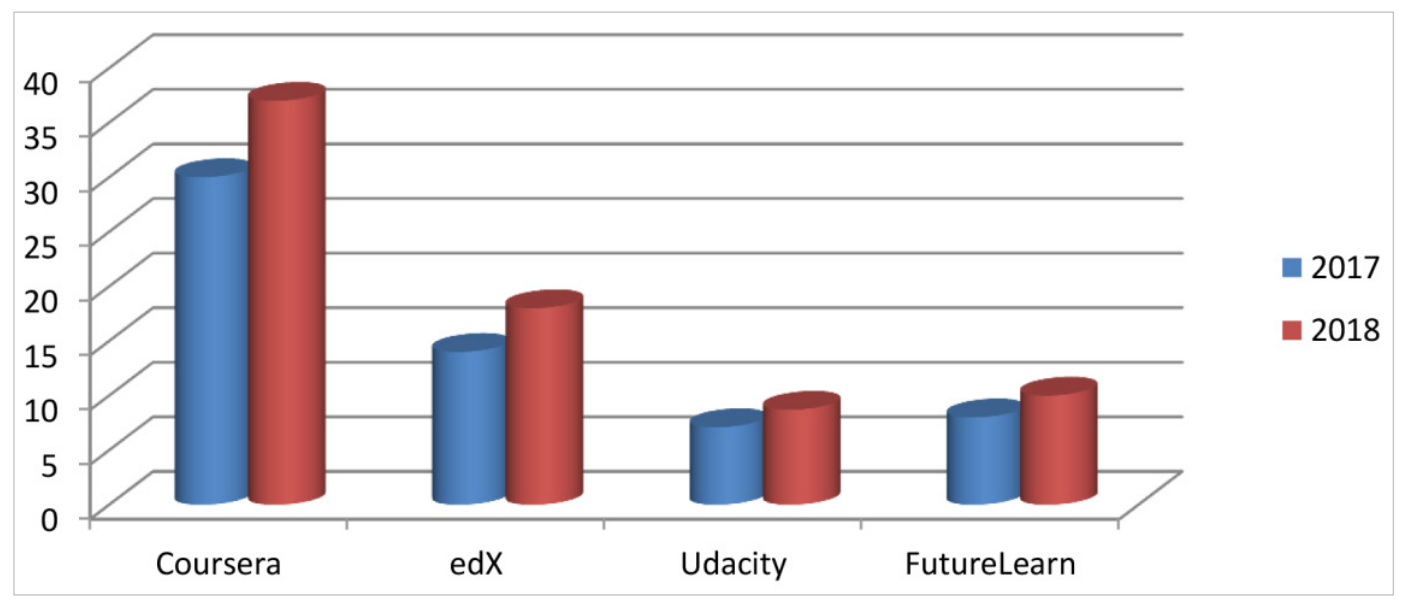

Figure 2. Main MOOC-platforms 
In addition, in the conditions of high competition between universities in the world, MOOC has become a new tool for promoting the educational brand of universities among potential applicants (including foreign students), as well as a platform to award certificates not only for individuals, but also for corporate clients, who can order the creation of a series of online courses to develop necessary competencies for their employees.

\section{Discussion}

Since 2015, both international and national platforms have been formed on the MOOC market. Universities and other organizations from various countries that produce online courses in different languages are represented in the international market of MOOC. The producers and consumers of such online courses are from different corners of the whole world. In contrast to the international market, providers of one or several countries that produce MOOCs in their native language are represented nationally.

While analyzing the data on the main directions of development of online courses, international and national aspects are highlighted in the works of such scientists and researchers as Shapiro H., Deng J., Semenova T., Foerster S., Liang D., Kizilcec R. and others $[13 ; 2 ; 12 ; 4 ; 8 ; 6]$. Depending on MOOC market whether national or international providers from different countries follow two behavioral strategies to create and promote online courses.

The first strategy involves the positioning and promotion of the country on the international MOOC market through the creation and placement of online courses on platforms whose users are citizens of foreign countries. The leading international providers include major American platforms edX and Coursera, which cooperate with organizations or universities from other countries which account for the largest number of students from different countries [8]. The second strategy is the promotion of online education in the domestic market to solve local problems. To implement it in the national platforms and/or resources of leading providers can be also used.

The first strategy is used mainly by countries in the Asian region, a number of European countries, as well as Arab countries. As a part of this strategy, online courses are being created in the international language (English) in various subject areas, including courses in subjects of educational programs, and MOOCs dedicated to the country's history, its cultural characteristics and language learning.

The second behavior strategy in the MOOC market is aimed at solving internal tasks of the state, while national platforms or leading resources can be used [9]. "Open Learning" platform is an Australian provider of open online courses which hosts mainly courses from Australian and Malaysian universities. Russian universities and organizations place their own online courses on both leading and national platforms. At the beginning of 2018, the National Open Education Platform hosted 259 courses. On leading platforms (Coursera and edX) from Russian institutions, 256 MOOCs are represented out of which only $25 \%$ are made in a foreign language. At the same time, a number of online courses from Russian providers on leading platforms are steadily growing. If in 2017 Coursera and edX users were offered 48 MOOCs in English, at the beginning of 2018 it was already 63 [7].

We estimate the MOOC international market on the basis of analytical data presented in Class Central MOOC reports, as well as a list of online courses hosted on major platforms such as Coursera and edX. In 2018, MOOCs devoted to the humanities accounted for about $10 \%$ of all courses that were hosted on international platforms. A choice of courses to study foreign languages is very limited. In most cases, there are courses of learning English from basic to advanced levels on the platforms [6].

In addition, it is possible to find courses aimed at developing individual English language skills such as speaking, listening comprehension, plus rules of punctuation. Some courses are accompanied by subtitles in Chinese or Spanish, which increases the demand of the audience who speak little English. The second most popular language after English is Chinese. According to the analytics of the Class Central platform, one can distinguish entry-level courses in all subject areas, which are of an introductory nature to advanced courses. Russian universities and organizations place their own online courses on both leading platforms and national ones. At the beginning of 2018, the National Open Education Platform hosted 259 courses. On leading platforms, Coursera and edX 256 MOOCs from Russian institutions are represented, just $25 \%$ of which are recorded in a foreign language. At the same time, the number of online courses from Russian providers is steadily growing on leading platforms.

\section{Recommendations}

The study records can be used to create massive open online courses, in the preparation of relevant lecture courses or teaching aids for students. This work has also practical significance in studying the main trends of distant learning development, so the paper given is of great interest to researchers, teachers, and students.

\section{Conclusions}

Researchers in this area evaluate the benefits and risks of using MOOC in education in a similar way. Among the advantages, accessibility and massive involvement dominate other parameters of quality education. Both teachers and students agreed in their positive assessment of general subjects' replacement with the MOOC, and at the same time they are quite restrained or negative about 
the replacement of special (professional) subject matters. The main problems and risks of using a MOOC are related to the lack of necessary feedback from the teacher, weak incentives to complete the training in the absence of constant external control, and unreliable identification of the listener during the assessment.

An analysis of the MOOC market indicates an intensive growth in the number of MOOC manufacturers and providers, as well as the number of participants in online courses. Millions of people around the world are in need of high-quality while affordable education and therefore they are looking for opportunities for professional and personal growth, consequently the world's leading countries are actively involved in an online education competition. Putting MOOCs of Russian universities in a foreign language on the MOOC international market will allow Russia to solve a number of cultural, political and economic problems. International platforms can be considered as a means of popularizing their own culture, as an opportunity to draw attention to their history, as well as modern, scientific, and technical developments.

\section{Acknowledgement}

The work is performed according to the Russian Government Program of Competitive Growth of Kazan Federal University.

\section{REFERENCES}

[1] De Barba, P., Kennedy, G., Ainley, M. (2016). The Role of Students' Motivation and Participation in Predicting Performance in a MOOC. Journal of Computer Assisted Learning, 32(3), 218-231.

[2] Deng, J. (2017). Research on Higher Vocational Students' Acceptance and Use of MOOC in Web Software Development Course. Boletín Técnico, 55(7), 689-695.

[3] Fakhrutdinova, A. V. , Shamsutdinova, D. V., Kalimullina, O. A., Ivanova, A. V. (2018). Influence of multicultural environment of educational organisation on students individual development. Abstracts \& Proceedings of ADVED 2018 - 4th International Conference on Advances in Education and Social Sciences, 15-17 October - Istanbul, Turkey ISBN: 978-605-82433-4-7.

[4] Foerster, S. H. (2017). Global: Relax-Higher Education Won't Be Killed By MOOCs. Understanding Global Higher Education. Global Perspectives on Higher Education (eds G. Mihut, P. G. Altbach, H. Wit), Rotterdam: Sense Publishers, 151-153.

[5] Gyshchina, O. M., Mikheeva, O. P. (2017). Massive open online courses for pedagogical staff training. The Education and Science Journal, 7(19), 119-136. DOI: 10.17853/1994 $-5639-2017-7-119-136$.

[6] http://www.edutainme.ru/post/MOOS-2018/ (accessed 18
April 2019).

[7] http://www.edutainme.ru/post/rossiya-na-coursera-v-tsifrak h/ (accessed 18 April 2019).

[8] Kizilcec, R., Saltarelli, A., Reich, J., Cohen, G. (2017). Closing Global Achievement Gaps in MOOCs. Science, 355(6322), 251-252.

[9] Klimentyev, D., Klimentyeva, V. (2015). Optimizatsiya akademicheskikh obrazovatelnykh programm rossiyskikh vuzov za schet ispolzovaniya massovykh otkrytykh onlayn-kursov [Optimization of Russian Higher Education Academic Programs by Means of Massive Open Online Courses]. Vestnik Permskogo natsionalnogo issledovatelskogo politekhnicheskogo universiteta. Problemy yazykoznaniya i pedagogiki, 4(14), 22-27.

[10] Liang, D., Jia, J., Wu, X., Miao, J., Wang, A. (2014). Analysis of Learners' Behaviors and Learning Outcomes in a Massive Open Online Course. Knowledge Management \& E-Learning, 6(3), 281-298.

[11] Patru, M., Balaji, V. (eds) (2016). Making Sense of MOOCs: A Guide for Policy-Makers in Developing Countries. Available at: http://unesdoc.unesco. org/images/0024/0024 51/245122E.pdf (accessed 18 April 2019).

[12] Phan, T., McNeil, S. G., Robin, B. R. (2016). Students' Patterns of Engagement and Course Performance in a Massive Open Online Course. Computers \& Education, 95, $36-44$.

[13] Phan, T., McNeil, S. G., Robin, B. R. (2016). Students' Patterns of Engagement and Course Performance in a Massive Open Online Course. Computers \& Education. 95, $36-44$.

[14] Semenova, T. F., Vilkova, K. A., Shcheglova, I. A. (2018). The market of massive open online courses: perspectives for Russia. Voprosy obrazovanija, 2, 173-197.

[15] Shapiro, H. B., Lee, C. H., Wyman Roth, N. E., Li, K., Cetinkaya-Rundel, M., Canelas, D. A. (2017). Understanding the Massive Open Online Course (MOOC) Student Experience: An Examination of Attitudes, Motivations, and Barriers. Computers \& Education. 110, 35-50. https:// doi.org/10.1016/j.compedu.2017.03.003

[16] Tong, T., Li, H. (2017). Demand for MOOC — an Application of Big Data. China Economic Review. January, $1-14$.

[17] Tejeda, S., \& Dominguez, A. (2019). Influence of Interactions in the Collaborative Solving of a Velocity Problem. International Electronic Journal of Mathematics Education, 14(1), 91-108. https://doi.org/10.12973/iejme/3 979

[18] Taubaye, Z., Rivers, W., Mussabekova, U., \& Alimbayeva, A. (2018). Peculiarities and problems of eponyms (on the material of Kazakhstani periodicals). Opción, 34(85-2), 221-236.

[19] Tabatabaei, F., Karahroudi, M. M., \& Bagheri, M. (2014). Monitoring and zoning sultry phenomena in the southern provinces of Iran, UCT Journal of Social Sciences and Humanities Research, 2(3): 1-8. 